\title{
The Influence of Police Training Programmes on Police Officers Participation in Gender Based Violence Prevention in Uganda
}

\author{
Sseggiriinya Fredrick* \\ College Of Education And External Studies, Makerere University \\ P.O. Box 7065 Kampala, Uganda. \\ Ezati Betty \\ College Of Education And External Studies, Makerere University. \\ P.O. Box 7065 Kampala, Uganda \\ Wafula Wycliff Scot \\ College Of Education And External Studies, Makerere University \\ P.O.Box 7065, Kampala.Uganda
}

\begin{abstract}
This study sought to investigate the influence of police training programmes on police officers participation in gender based violence prevention in Uganda. The investigation was provoked by the reportedly deteriorating performance of police officers in areas of gender based violence prevention despite of government's effort to transform Uganda to a middle income country by 2040. The specific areas studied were the influence of police training on their participation in enforcement of laws related to gender based violence prevention, creating awareness on gender based violence prevention to the community and police officers efforts to prevent gender based violence. The study took an interpretive philosophical paradigm and was under pined by the Social learning theory and the Expectancy theory of Motivation. Data was collected using questionnaires, interviews, Focused Group Discussions, participant observation and documentary analysis. A total of 412 police officers and 80 non police officers participated in the study. Quantitative data was analyzed using SPSS by use of descriptive statistics, correlation analysis, Regression analysis and Analysis of Variance (ANOVA) while qualitative data was analyzed using thematic analysis by use of transcription, coding and themes development. The study findings showed a strong positive relationship between training programmes and participation in gender based violence prevention, $(\mathrm{r}=0.530, \mathrm{p}=0.000, \mathrm{n}=412)$. It further showed that police training programmes are predictors of police officers participation in gender based violence prevention, $\mathrm{pv}<0.050(=0.000)$. The relationship is statistically significant at $95 \%$ confidence level. The researcher concluded that police training programmes influence police officers participation in gender based violence prevention in Uganda. Thus it was recommended that police management promote community awareness on gender based violence prevention by allocating enough funds to standardize training and other activities related to gender based violence prevention in Uganda.
\end{abstract}

Keywords: Police Training Programmes Gender Based Violence Prevention.

DOI: $10.7176 /$ RHSS/9-20-05

Publication date:October $31^{\text {st }} 2019$

\subsection{BACKGROUND TO THE STUDY}

This study sought to find out how police training programmes influence police officers' participation in gender based violence prevention in Uganda. In this study police training programmes means an inventory of activities, content and/or methods implemented to achieve police training objectives (acquiring/imparting knowledge, skills and/or competences), organized in a logical sequence over a specified period of time. while Gender based violence prevention (GBVP) means stopping any harmful act that is perpetrated against a person's will basing on biological, sex, gender identity or perceived adherence to socially defined norms of masculinity and femininity, including acts, threats, coercion or arbitrary deprivations of liberty whether occurring in public or private life in form of economic, physical, sexual or emotional from happening.

The study was carried out between 2014 -2019. The study only covered police officers participation in GBVP. The study hypothesis was stated as: Police training programmes influence police officers participation in gender based violence prevention in Uganda. It was guided by the question which stated that: How do police training programmes influence police officers participation in gender based violence prevention in Uganda?. It only investigated the initial police training programmmes because they are mandatory to all police officers irrespective of the level of entry. According to the Uganda police force training policy ( 2014) and the Uganda Police Force curricula for cadet assistant superintendents of police (2015) and probationer police constable (2015), Police officers are expected to go into thorough training and thereafter participate into gender based violence prevention (Uganda Constitution 1995 as amended, The national policy on elimination of gender based violence in Uganda 2016, Uganda National Gender Policy 2017, Police Act, Police Standing Order, Uganda police force Gender 
Policy 2018, Uganda police force Human Rights Policy 2019). However, their performance upon graduation seems not in tandem with what they study, for example in 2017 , the number of cases reported to police was 252,065 compared to 243988 cases in 2016 with common assaults, domestic violence, defilement threating violence , obtaining money by false pretense as the leading offences, thereby reflecting an increase in the volume of crime by $3.3 \%$. Defilement which is one of the dimensions of gender based violence was the leading crime and on increase with 12,077 cases reported in 2014 up from 9,598 in2013 which represents $26 \%$ increase (Uganda Police Force Annual Crime Report. 2017\& 2014). Failure to address these weaknesses will not only worsen gender based violence but will hinder the achievement of vision 2040 of a middle income country. Could the weaknesses in police performance be related to their training?

\subsection{RELATED LITERATURE AND METHODOLOGY.}

The reviewed literature revealed that police training influence police officers participation in gender based violence prevention ( Marissa \& Legaspi. 2015, Sreekumaran et al . 2017, Institute of Economic Affairs in India. 2009, Oehme et al .2016, Cara et al 2007, Retief \& Green. 2015, Lockwood \& Prohaska.2015, Felson \& Para . 2005, Joeden -Forgery. 2012). It also revealed that police gender desks are focal points where GBV cases are reported, investigated and perpetrators charged (United Nations Population Fund. 2008, United Nations Women Website, United Nations Office on Drugs and Crime. 2010).

It further revealed that police gender desks are facing various challenges such as lack of both human and non-human resources, and social - cultural issues (Kimani. 2009, UNFEM. 2000, National Gender \$ Equality Commission of Kenya. 2014, Wanjohi. 2016, Ndenje. 2014, Policy Brief- forum against GBV. 2012). The literature revealed that police officers in Uganda are among the key stakeholders in the prevention of GBV ( The National Policy on Elimination of Gender Based Violence in Uganda. 2016, The Uganda Gender Policy. 2017, The Uganda Police Force Gender Policy . 2018, The Uganda Police Force Human Rights Policy. 2019, The Children Diversion Guidelines for Police officers. 2019). For easy data presentation, analysis and interpretation respondents were categorized into police officers and non-police officers. Strongly agree and agree were presented as agreed yet strongly disagree and disagree were presented as disagreed. Only majority, s views were presented, $60 \%$ and above was interpreted as enough and needed to be upheld while $59 \%$ and below was interpreted as insufficient and needed improvement.

The study took an interpretive philosophical paradigm, mixed research methods and a survey design. All these were intended to help the researcher understand better the police officers and members of public analysis and interpretation of the police training programmes on police officer officers' participation in gender based violence prevention in Uganda. It would also help the researcher in assessing and validating complex situations in police training progeammes so as to make relevant, timely and applicable interventions . The parent population was the cohort of 2014 and 2010 police officers in takes as they had gone through the same curriculum and had stayed in the field for at least some time, so they could make rationale judgments if their initial training programmes enable them to participate in gender based violence prevention in Uganda. The study targeted 550 participants, 450 police officers and 100 members of public with a hope that this would give a confidence level of $95 \%$ and a margin of error of $=+$ or $-5 \%$ for this study .Due to factors beyond the researcher only 492 participated in this study, 412 police officers and 80 members of public which gave a response rate of $89.5 \%$. For the known population sizes, sample sizes were determined by using Krejcie and Morgan (1970) sample size determining table, effect size and sample size calculator while for the unknown population, the sample size was delivered by computing the minimum size. Sampling techniques included Snowball, random, purposive and convenience sampling. Instruments used to collect data were questionnaires, interviews, observational checklist, and documentary analysis and focused group discussions'. Validity of the instrument was determined by calculating the Content Validity Index while reliability was established using the Cronbach Alpha Coefficients.

Qualitative data analysis stated by transcribing, coding and themes development which presented data in a concise, logic, non- repeated and interesting account. Trustworthiness of qualitative data was ensured by ensuring credibility, transferability, dependability, conformability, keeping audit trails and reflexivity. Quantitative data analysis was done by developing tables, computation of corresponding percentages from the responses obtained, coding of key words and phrases in order to pinpoint common responses. Tallies and frequency counts were made and then percentages calculated. These were presented in tables to graphically represent all the categories and sub categories of the data got from the entire participants. Five strategies were employed to ensure the quality of quantitative data in this study and these were a large sample size which gave a response rate of $89.5 \%$, thorough and rigorous process of developing the questionnaire like consulting lectures, my two lead supervisors and course mates. Thirdly by piloting the questionnaire fourthly respondents answered the questionnaire in one session under supervision so that uncertainties could be clarified immediately and finally by obtaining a content validity ratio of 0.80 which is an essential figure for an object. Mixed methods validity/ data legitimation was by sample integration, inside - outside, weakness minimization, sequential, conversation, paradigmatic mixing, commensurability, multiple validities and political. 
3.0 Data Presentation, Analysis, Discussion and Interpretation.

\begin{tabular}{|l|l|l|l|}
\hline Response category & $\begin{array}{l}\text { Targeted sample } \\
\text { size }\end{array}$ & $\begin{array}{l}\text { Actual number } \\
\text { respondents }\end{array}$ & $\begin{array}{l}\text { Response } \\
\text { Rate }\end{array}$ \\
\hline $\begin{array}{l}\text { Police training school } \\
\text { administrators }\end{array}$ & 8 & 8 & $100.0 \%$ \\
\hline Instructors & 125 & 111 & $88.8 \%$ \\
\hline Police graduates. & 312 & 268 & $85.9 \%$ \\
\hline District police leaders & 25 & 25 & $100.0 \%$ \\
\hline Members of public & 20 & 20 & $100.0 \%$ \\
\hline District leaders & 20 & 20 & $100.0 \%$ \\
\hline Community leaders & 20 & 20 & $100.0 \%$ \\
\hline Government agencies & 10 & 10 & $100.0 \%$ \\
\hline Non-government organisations & 10 & 10 & $100.0 \%$ \\
\hline Total & $\mathbf{5 5 0}$ & $\mathbf{4 9 2}$ & $\mathbf{8 9 . 5 \%}$ \\
\hline
\end{tabular}

Source: Primary data (2018)

Table 3. 1. Response rate

Table 3. 1 shows that the study had a response rate of $89.5 \%$ which means that the study had a reasonable response rate. It further shows that respondents included police officers and non-police officers meaning that the population was heterogeneous in nature which reflects unbiased findings, conclusions and recommendations in this study. Therefore the estimates can be generalized in line with the influence of police training programmes on police officers participation in gender based violence prevention in Uganda. A response rate of $89.5 \%$ shows the enthusiasm of the researcher and respondents on the influence of police training programmes and police officers participation in gender based violence prevention in Uganda.

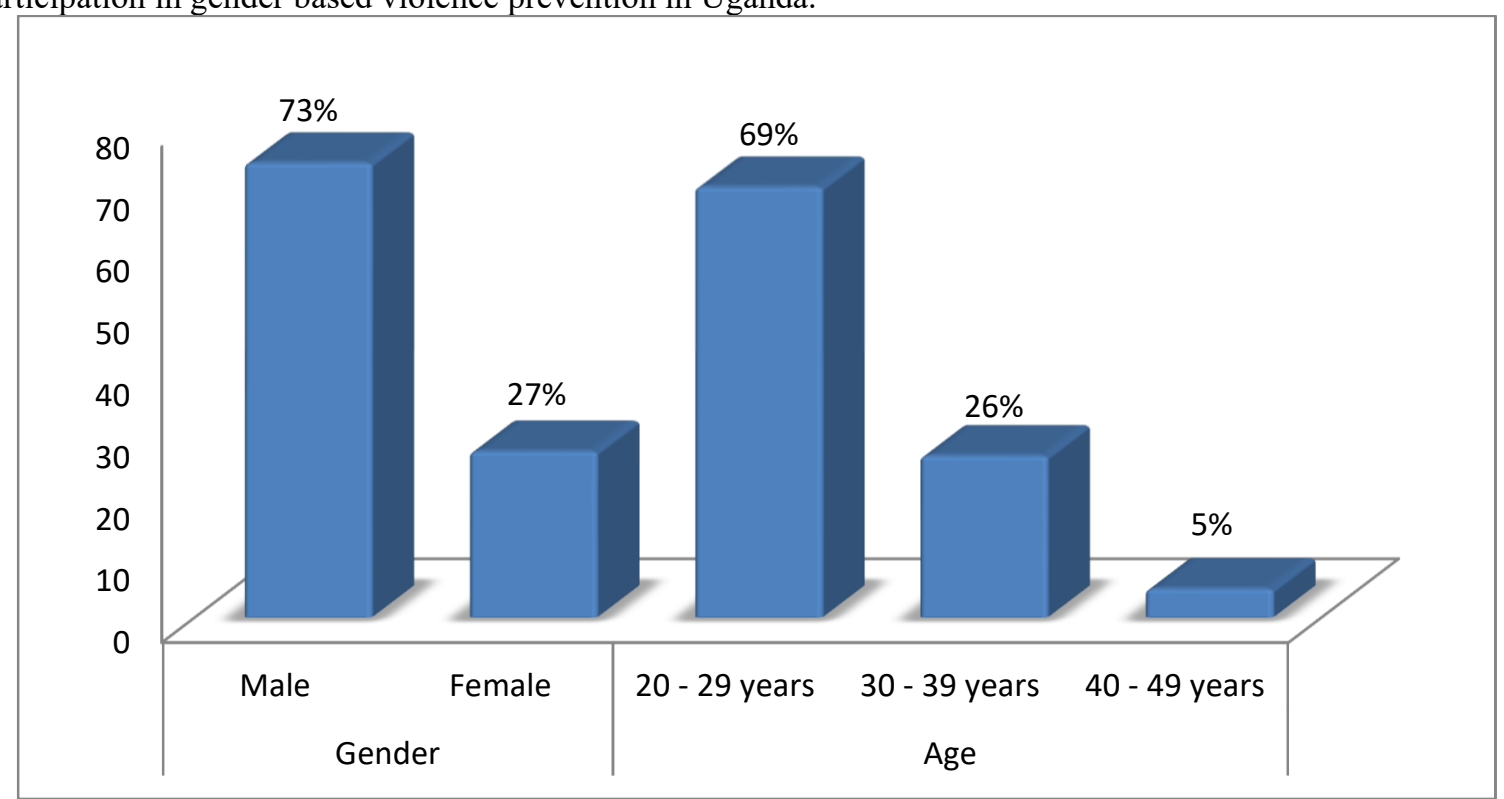

Figure 3. 1. Gender and age of the $\mathbf{4 1 2}$ police officers who answered the questionnaire

Figure 3.1 above shows that the majority of the police officers, 73 percent were male as compared to 27 percent that were female. In terms of age groups, the majority, 69 percent were aged $20-29$ years, whereas 26 percent were aged 30-39 years and five percent only were aged 40-49 years. This confirms the UPF Strategic policing plan 2014/15-2020 as on October 2014 that there are more male police personnel than female police personnel in UPF (5958 females compared to36752 male officers) and that majority of the personnel who participated in this study had gone through the same curriculum and are trainable. Secondary this is the age bracket where most Ugandans are facing challenges related to GBVP as they are out of schools.

The respondents' demographic characteristics of members of public in terms of gender, age, highest standard of education attained and marital status were sought. This was done in the quest to establish whether these characteristics of the respondents had an impact on the data they provided to this study about the police participation in GBVP in Uganda. 


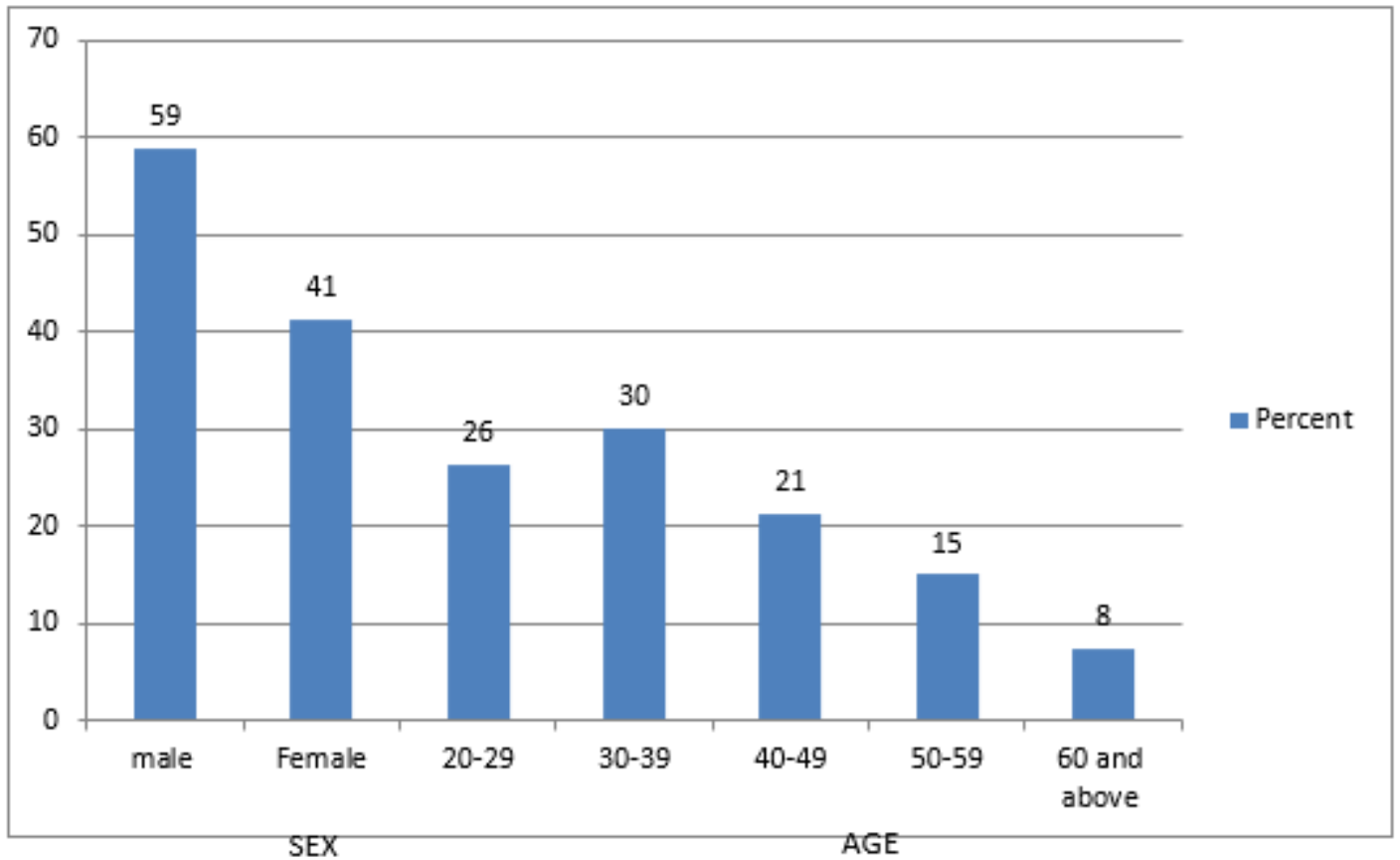

Figure 3. 2.Gender and age of the respondents

According to the results in Figure 3.2 above, more than half $59 \%$ of the study respondents were male and $41 \%$ were female. Despite of the observed disparity in favor of men, the study was gender inclusive since data was obtained from both male and female members of the public. This therefore implies that the study findings can be generalized to represent views of both male and female members of the public about police participation in GBVP in Uganda.

As indicated in the Figure 3. 2, the biggest proportion $30 \%$ of the study respondents were aged between 30 and 39 years of age, followed by $26 \%$ who were aged between $20-29$ years. $21 \%$ were between $40-49$ years. $15 \%$ of the respondents were aged between $50-59$ years and the last category of 60 years and above was represented by $8 \%$. This means that data were collected from mature people who understood well the study variables. Secondly, data was collected from different age categories of the members of public. This therefore implies that the study findings can be generalized to represent the views of the public at large about police participation in GBVP in Uganda.

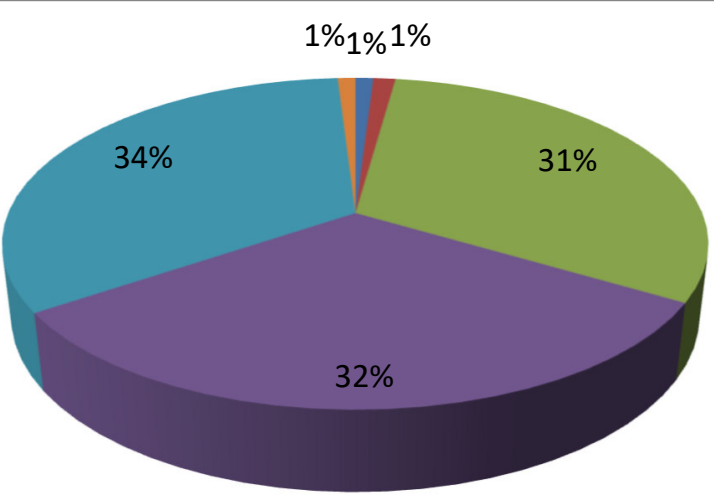

\section{Primary}

"O" Level

- "A" Level

- Diploma

- Graduate

- Post graduate

\section{Figure 3. 3. Highest Academic Standards of 412 police officers.}

Figure 3.3 above show that most of the police officers possessed "A" Level (31\%) (Higher secondary level of education), Diploma (32\%) or Graduate (34\%) levels of education. Respondents with Primary, "O" Level (secondary school level of education) or Post graduate levels of education were of negligible numbers. This means that the majority of respondents understood issues related to PTPs and police officers participation in GBVP and are trainable as they had attained a reasonable level of education. The respondents were asked about their highest standard of education to ascertain whether this had an impact on their knowledge about the police participation in GBVP in Uganda and results are presented in the figure 


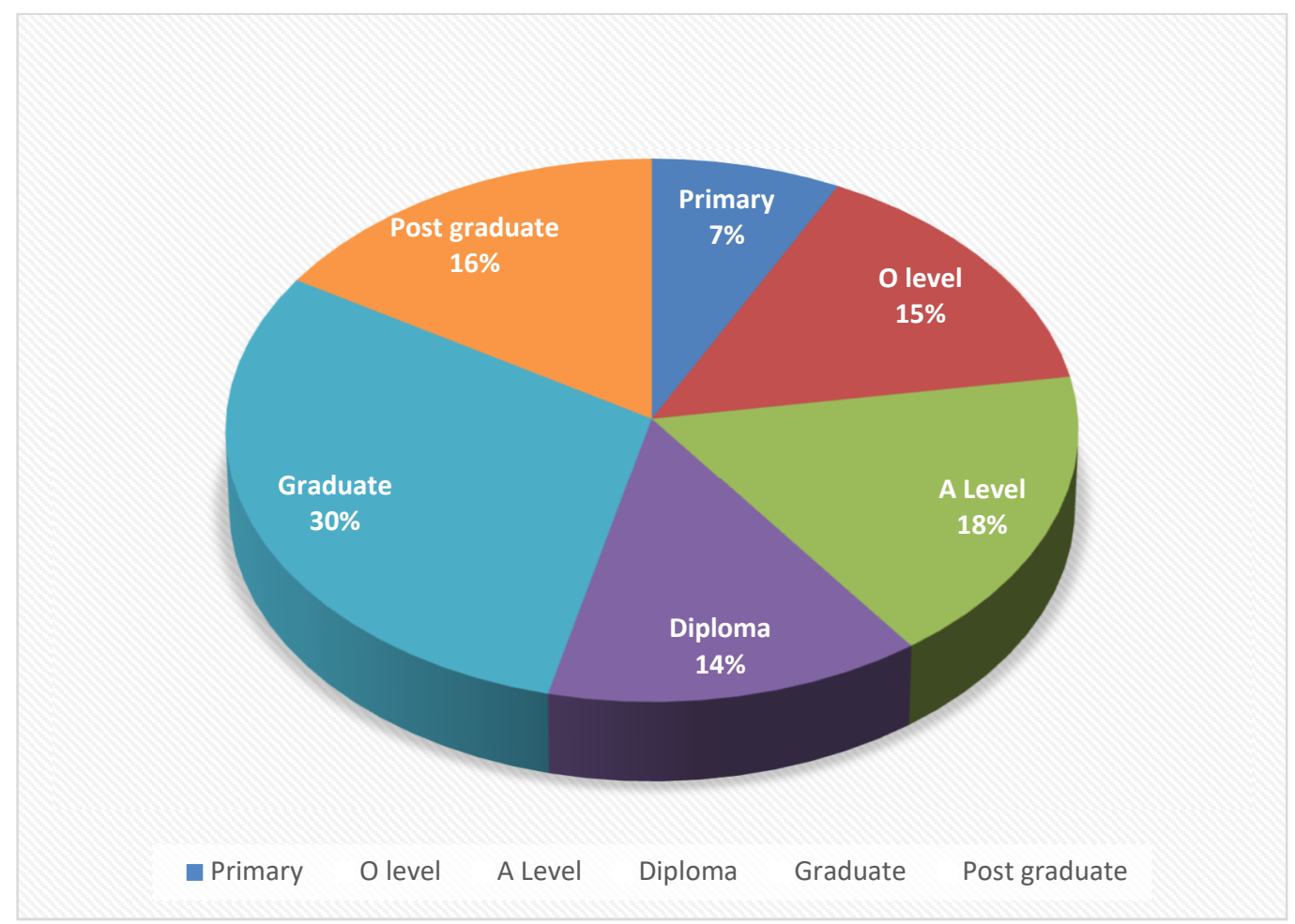

Figure 3. 4: Highest academic standards of 80 non police officers

The findings in Figure 3. 4, indicate that most $30 \%$ of the study respondents were educated up to degree level, followed by $18 \%$ who were educated up to Advanced level, then by $16 \%$ who had attained post graduate qualification, then by $15 \%$ who had finished Ordinary level, then $14 \%$ who had attained ordinary diploma qualifications and lastly by $14 \%$ who were educated up to primary level. This shows that data was attained from respondents of different education categories. This implies that the views of the general public were well represented in the study.

The marital status and period of service in the Uganda Police service by the respondents were also collected to assess whether they have a bearing on GBVP in Uganda and the findings are shown in the pie chart.

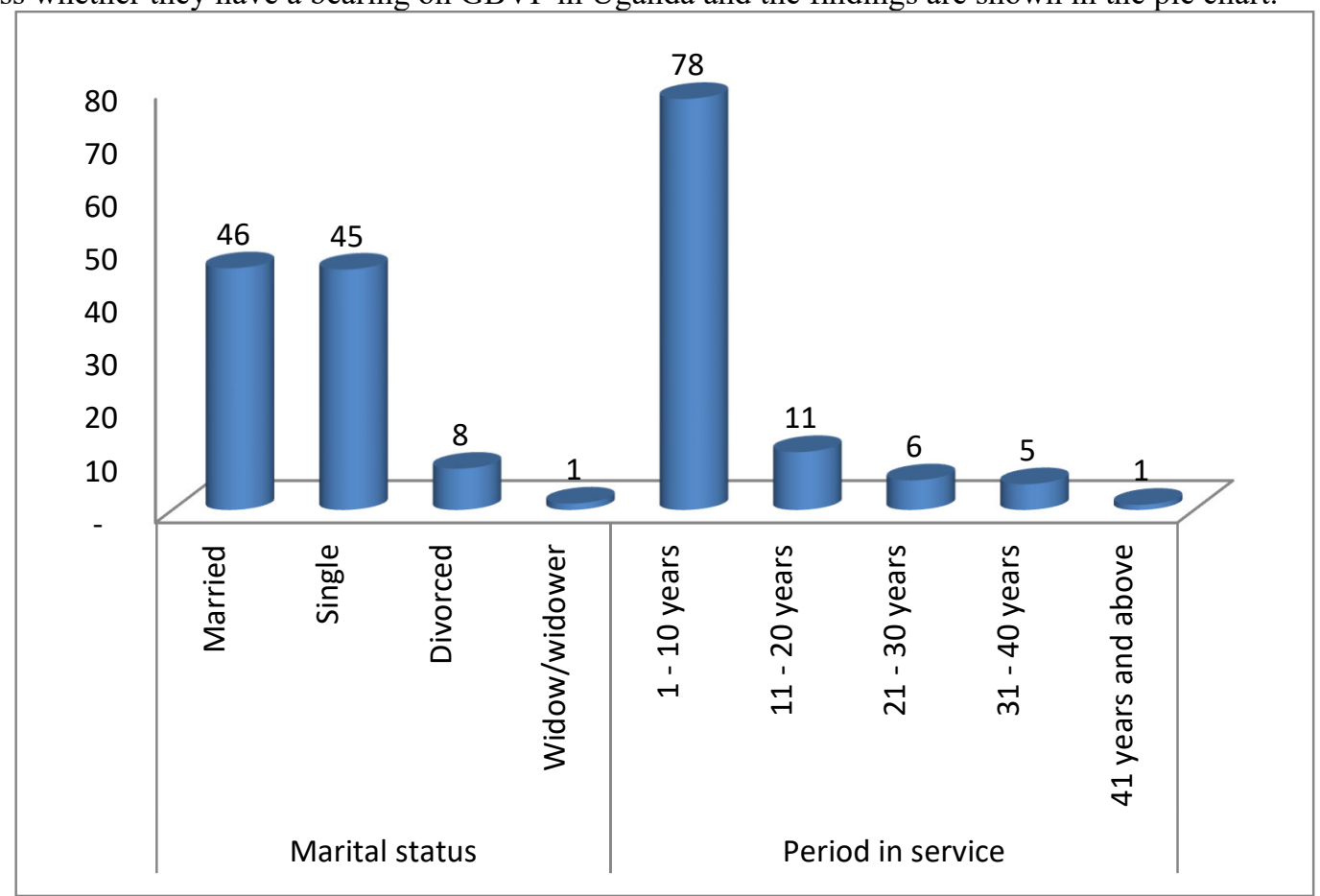

Figure 3. 5: Marital Status and Period in Service of the $\mathbf{4 1 2}$ police officers

Figure 3.5 above shows that police officers that were married (46 percent) were almost equal in number to 
those that were single (45\%), whereas the divorced constituted eight percent only and the windows/widowers comprised one percent only. In terms of period in service, the majority 78 percent had served between $1-10$ years, while 11 percent has served $11-12$ years and those that had served over 20 years were generally negligible in number. This means that majority of the respondents had experience to better apply personnel knowledge, understanding, skills, attitude and behavior on issues related to PTPs and police officers participation in GBVP as they had gone through the same current curriculum. Questionnaire for members of public only sought their opinions and views on what police has done and what should do in the studied areas. The marital status of the respondents was captured and this was intended to assess whether this had an impact of the views that they gave about the police participation in GBVP in Uganda. Results are presented in the chart.

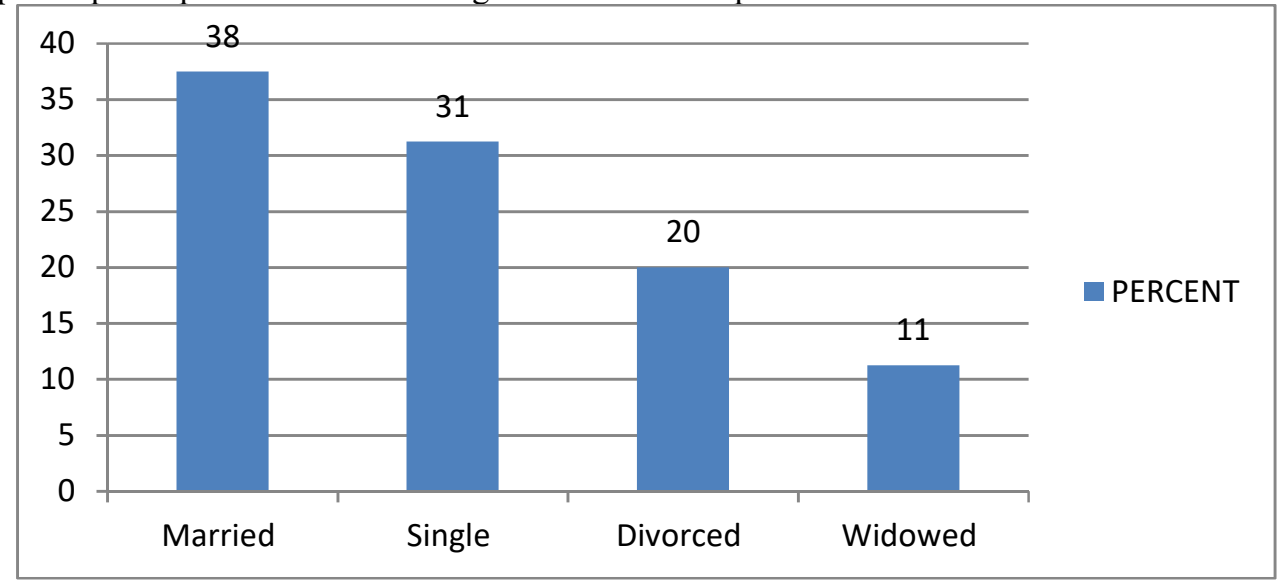

Figure 3. 6: Marital status of the 80 non-police officers

The findings in Figure 3.6 indicate that most $38 \%$ of the study respondents were married, $31 \%$ were single, $20 \%$ were either divorced or separated from their partners and lastly $11 \%$ were widowed. This shows that data was obtained from all the categories and this implies that it was free of marital bias and can be used to represent the views of the general public about police participation in GBVP in Uganda.

The hypothesis was guided by the question. How have police training programmes influenced police officers participation in the prevention of gender based violence in Uganda?

In order to understand the views of the respondents on training programmes, so as to establish whether they have influence on police officers prevention of gender based violence, the study used fifteen statements on the questionnaire to which the respondents were required to show their level of agreement or disagreement.

Qualitative findings from interview guide and unstructured questions were used to substantiate the quantitative findings. The quantitative findings from the 412 police officers that answered the questionnaires are presented in Table 3.2. 


\begin{tabular}{|c|c|c|c|c|c|}
\hline \multirow[t]{2}{*}{ Statements } & \multicolumn{5}{|c|}{ Percentage } \\
\hline & $\mathbf{S A}$ & $\mathbf{A}$ & D & SD & $\mathbf{N S}$ \\
\hline \multicolumn{6}{|l|}{ Training: } \\
\hline $\begin{array}{l}\text { Police officers are adequately Trained on gender based violence prevention } \\
\text { in Uganda }\end{array}$ & 7 & 48 & 36 & 7 & 2 \\
\hline $\begin{array}{l}\text { Police Trainers cover Gender Based Violence Prevention in Uganda } \\
\text { adequately during the initial police training programmes. }\end{array}$ & 7 & 44 & 42 & 5 & 2 \\
\hline $\begin{array}{l}\text { Time allocated to cover Gender Based Violence prevention content during } \\
\text { initial police training programmes is enough }\end{array}$ & 13 & 43 & 39 & 5 & 0 \\
\hline $\begin{array}{l}\text { The assessment methods during initial police training programme facilitated } \\
\text { learning on GBV prevention }\end{array}$ & 7 & 51 & 34 & 6 & 2 \\
\hline $\begin{array}{l}\text { The training methods during initial police training programme facilitated } \\
\text { learning on GBV prevention }\end{array}$ & 5 & 48 & 40 & 4 & 3 \\
\hline $\begin{array}{l}\text { The instructional strategies during initial police training programme } \\
\text { facilitated learning on GBV prevention }\end{array}$ & 5 & 46 & 41 & 4 & 4 \\
\hline \multicolumn{6}{|l|}{ Performance: } \\
\hline $\begin{array}{l}\text { Police officers promote community awareness on gender based violence } \\
\text { prevention in Uganda. }\end{array}$ & 6 & 60 & 31 & 3 & 0 \\
\hline Police officers enforce laws on gender based violence prevention in Uganda & 4 & 56 & 36 & 3 & 1 \\
\hline $\begin{array}{l}\text { Police officers assist victims of gender based violence prevention at police } \\
\text { stations/posts in Uganda }\end{array}$ & 5 & 57 & 29 & 8 & 1 \\
\hline Police officers practice gender based violence prevention in Uganda & 7 & 56 & 33 & 3 & 1 \\
\hline $\begin{array}{l}\text { Perpetrators of gender based violence in Uganda are counseled by police } \\
\text { officers }\end{array}$ & 5 & 53 & 33 & 7 & 2 \\
\hline Police officers carry out referrals to gender based violence victims in Uganda & 8 & 42 & 41 & 7 & 2 \\
\hline Police has enough resources to prevent gender based violence in Uganda & 11 & 43 & 34 & 8 & 4 \\
\hline $\begin{array}{l}\text { Police officers have knowledge, understanding, skills, attitude and behavior } \\
\text { to handle gender based violence cases in Uganda in time }\end{array}$ & 8 & 59 & 28 & 3 & 2 \\
\hline $\begin{array}{l}\text { Witnesses of Gender Based Violence cases are protected by police officers } \\
\text { in Uganda. }\end{array}$ & 6 & 55 & 29 & 7 & 3 \\
\hline
\end{tabular}

Source: Primary data (2018)

Table 3. 2. Police officers prevention of gender based violence.

Training was one of the dimensions used to measure police officers prevention of gender based violence and the findings are here under presented. Strongly agreed and agree responses are both presented as agree, whereas strongly disagreed and disagree responses are both presented as disagreed. On the issue of whether Police officers are adequately trained on gender based violence prevention in Uganda, the majority, $55 \%$ agreed; $7 \%$ strongly agreed and $48 \%$ agreed. This means that police officers are trained on GBV during police training programmes in Uganda.

Table 3.. 2 further shows that on whether Police trainers cover gender based violence prevention content in Uganda adequately during the initial police training programmes, the majority, $51 \%$ agreed; $7 \%$ strongly agreed and $44 \%$ agreed. Still this means that police trainers in Uganda cover GBV during police training. On whether time allocated to cover Gender Based Violence prevention content during initial police training programmes is enough, the majority, $56 \%$ agreed; $13 \%$ strongly agreed and $43 \%$ agreed. Also this means that time to cover GBV prevention content is allocated during police training programmes in Uganda.

On whether the assessment methods during initial police training programme facilitated learning on GBV prevention, the majority, 58\% agreed; $7 \%$ strongly agreed and 51\%agreed. This means that the assessment methods during police training programmes in Uganda facilitate police officers learning of GBV prevention. On the issue of whether the training methods during initial police training programme facilitated learning on GBV prevention, the majority, $53 \%$ agreed; $5 \%$ strongly agreed and $48 \%$ agreed. This means that the training methods during police training in Uganda facilitate learning on GBV prevention. Finally on whether the instructional strategies during initial police training programme facilitated learning on GBV prevention, the majority, $51 \%$ agreed; $5 \%$ strongly agreed and $46 \%$ agreed. Also this means that the instructional strategies during police training in Uganda facilitate learning on GBV prevention.

Table 3. 2 shows that the majority of the police officers, $66 \%$ agreed that Police officers promote community awareness on gender based violence prevention in Uganda; $6 \%$ strongly agreed and $60 \%$ agreed. This suggests that police training influences police officers participation in gender based violence prevention in Uganda. On whether Police officers enforce laws on gender based violence prevention in Uganda, the majority, $60 \%$ agreed; $4 \%$ strongly agreed and $56 \%$ agreed. This means that police training in Uganda influences police officers 
enforcement of laws related to gender based violence prevention. On the issue of whether Police officers assist victims of gender based violence prevention at police stations/posts in Uganda, the majority of the police officers, $62 \%$ agreed; $5 \%$ strongly agreed and $57 \%$ agreed. This means that police training influences police officers assistance to victims of gender based violence at police stations/posts in Uganda.

Furthermore on whether Police officers practice gender based violence prevention in Uganda, the majority, $63 \%$ agreed; $7 \%$ strongly agreed and $56 \%$ agreed. This means that police training influences police officers participation in gender based violence prevention in Uganda. In order to find out further how police provide gender based violence prevention, an interview was held with an official from a government organization and had this to say" police has established departments of Child and family protection departments at headquarters, regional and district headquarters, carry out community awareness to the public on the dangers of GBV, and work hand in hand with our personnel at various levels. These departments have helped provide gender based violence prevention to the communities".

In a FGD with six police officers on the same, the following were obtained "Police apprehends and prosecutes offenders of GBV, assist victims, counsels both offenders and victims, carries out referrals, it is one of the modules in our curriculum and carries out community awareness". In FGD with members from Non-Government Organizations that advocate for the end of GBV in Uganda on what police should do to end GBV in Uganda, the following responses were got: police officers should be given enough resources so that they stop demanding facilitation from victims and suspects of GBV, more trainings should be given to police officers on GBV so that cases do not fail due to lack of sufficient and collaborative evidence and poor statement recording, more decent structures like counseling room, holding Centres together with other requirements like mattresses, basins, chairs and food be constructed and provided at the police stations.

Table 3. 2 further shows that on whether perpetrators of gender based violence in Uganda are counseled by police officers, the majority of the police officers, $58 \%$ agreed; $5 \%$ strongly agreed and 53\% agreed. On whether Police officers carry out referrals to gender based violence victims in Uganda, the majority, $50 \%$ agreed; $8 \%$ strongly agreed and $42 \%$ agreed. This means that police training programmes influence on police officers to carry out referrals to GBV victims. Asked further whether Police has enough resources to prevent gender based violence in Uganda, the majority, 54\% agreed; $11 \%$ strongly agreed and 43\% agreed. This means that police has some resources to handle GBV in Uganda

On the issue of whether Police officers have knowledge, understanding, skills, attitude and behavior to handle gender based violence cases in Uganda in time, the majority, $67 \%$ agreed; $8 \%$ strongly agreed and $59 \%$ agreed. This means that police training influences police officers knowledge, understanding, skills, attitude and behavior to handle GBV cases in Uganda. Table 2 further shows that on whether witnesses of Gender Based Violence cases are protected by police officers in Uganda, the majority, and 61\% agreed; $6 \%$ strongly agreed and $55 \%$ agreed. This means that police training in Uganda influences police officers protection of witness in GBV cases. In order to find out further what police should do to prevent GBV in Uganda, an interview was held with one of the country coordinator of a Non-Government Organization and had this to say "police needs to standardize its training; police should emphasis non-conventional methods of training, the training policy and curriculum needs to be reviewed".

On the question what police has done to prevent GBV, from police officers the following thematic themes were finally developed. Police has incorporated GBVP into its curricula at all levels and has manuals on GBVP for Initial courses, UPF has a Gender policy which is both inner and outside looking i.e. caters for gender matters in and outside police. .Police has established departments to specifically handle gender related crimes and other matters. Such departments include Women Affairs, Child and Family Protection, Sexual and Gender based violence department under the Directorate of Criminal Investigations, ,Police partners with other stakeholders to prevent GBV. Partners include Government departments under Justice, Law and Order Sector, Non - Government Organisations, members of public, Police budget is gender based focused, Police training programmes are gender based focused with a $30 \%$ female ratio and has Standard Operating Procedures during and after Trainings. It is one of the areas for its community policing programmes and Police enforces laws related to gender based violence.

When police officers were asked on what police should do to end Gender Based Violence Prevention in Uganda, responses were generated under the following thematic themes.

Police should review its curricula and training manuals to include sexual and health reproductive rights, social norms, accountability and monitoring mechanisms, operationalize the established departments up to the lowest police units. ,allocate more funds to gender based violence prevention programmes and revise police forms or gazette a particular police form for gender based violence related crimes. Respondents from members of public noted that the UPF have been recording GBV cases and have provided statistics of reported cases. Respondents acknowledged that UPF was providing security to GBV victims/survivors and sensitizing communities on the implications of GBV crimes. Respondents also noted that UPF has provided a toll free hotline where communities report GBV cases for rapid response. In addition, the respondents from members of public raised a number of steps that can be taken by police to prevent GBV in communities and noted that the UPF should build and equip police 
stations to carry out timely GBV investigations, and to facilitate timely apprehension of perpetrators/suspects. Respondents pointed out that UPF needs to prioritize funds towards internal development and reviews of curriculum to include GBV include sexual and reproductive health rights, social norms, and monitoring and evaluation mechanisms. Respondents noted that GBV section be offered sufficient office space, equipment to store exhibits, motor vehicles and fuel for GBV/SGBV investigations.

In FGD with officials from the government departments on the same, the following were got (1) police develop curricula for various courses (2) police develop training manuals (3) police develop trainers guides (4) conduct training needs assessments regularly (5) put in place quality assurance measures, guidelines and minimum standards for a police training school, (6) create a data bank for trainers and trainees (6) implement the police training policy. In addition, members came up with the following issue to be included in the police curriculum: (1) communication skills (2) sign language (3) French (4) Arabic (5) International and regional laws, protocols, treaties and policies on GBV prevention. In another FGD with police officers on what non-conventional methods of training should police undertake? , the following were generated (1) coaching (2) mentoring (3) delegation feedback (4) taskforce activities (5) attachments (6) study visits (7) exchange visits (8) twining programmes (9) rotations and transfers (10) research (11) distance learning (12) detachments (13) benchmarking for comparison purposes.

In an interview with the district leader to find out what police should do to prevent GBV in Uganda, she replied that" police should focus on scientific based policing skills development". When probed further to mention such scientific based policing skills which are needed, she replied that "forensics science and ICT. In order to find out further which forensics science and ICT is needed by police to end GBV, a FGD was held with police officers and members of the community and the following answers were got: (1) criminal identification skills like finger printing, blood samples, sexual liquids, sweat, and silver, (2) questioned documents.(3) Ballistics science (4) cyber-crimes (5) chemical analysis such as DNA, Texilogy, drugs, water, and environment (6) use of closed circuit television, (7) electronic counter measures like photographic interpretation, writing expertise skills interpretation (8) chemical, Radiological, Biological and nucleus caused related offences, (9) voices analysis. Another interview with another country coordinator of a Non-Government Organization to find out what police should do to prevent GBV in Uganda was held; he replied that "police should train its officers on International and Regional laws, treaties, protocols and declarations on GBV which seems to be lacking among police officers". From all the FGDs and interviews, underfunding aspect came to be the common issue far as GBVP is concern. In order to find out further which International and Regional laws, treaties, protocols and declarations should be taught to police officers, a FGD was held with members from government departments non-government organisations which deal with matters concern with GBVP, they all agreed that there is need to train police officers on the international and regional laws, treaties, protocols and declarations which are concern with GBVP.

Documentary review revealed that UPF has a module on SGBVP and child protection in the initial curriculum for C/ASPs and PPCs The content/topics in this module are (1) definition of sexual and gender related concepts(2) introduction to SGBVP (including forms), (3)myths and stereotypes,(4) causes and consequences of SGBVP, (5) legal frame work and international legal frame works, (6) offences and penalties,(7) SGBVP as human rights violation,(8) domestic violence,(9) characteristics of suspects, victims / survivors of SGBVP, (10) guiding principles (safety, respect, confidentiality),(11) roles of police officers in response to and prevention of SGBVP(processes and procedures of handling SGBVP cases),(12) gender mainstreaming in UPF, (13) interpretation of the children's Act, (14) rights of the child, (15) child rights violation,(16) juveniles in contact and conflict with the law (survivors /victims and those that need protection from police),(17)interviewing child witnesses and victims/ survivors, (18) juvenile justice system(diversions and referrals), (19) roles of stakeholders in child protection (duties of probation officers etc.). This module has 39 total lecture hours, 27 total tutorial hours, 10 total practical hours, 76 total contact hours and 4total credit units. The mode of assessment for this module is by written examinations (intermediate and final) which is out of $50 \%$, classroom assignment/coursework which is out of $15 \%$, practical assignment which is out $30 \%$ and peer rating which is out of $05 \%$. The pass mark for this module is $50 \%$.Resource persons had formal education in various disciplines, the lowest being Advanced certificate of education with a minimum experience of five years in police force and had done several courses related to police work. Methods of delivery included lectures, guided discussions, simulations and practical. The module has course codes, course level, course description and learning outcomes with a list of reference materials and equipment as well as the ranks/ tittles of resource persons.

Also the review of Human Rights Training Manual for the UPF produced by the Uganda Human Rights Commission and UPF confirmed that police officers are trained on sexual and gender based violence prevention. The Trainer's guide for UPF on Human Rights, GBV and child protection developed by United Nations Human Rights, UNICEF, UNFPA and UPF was revealed during this study. This revealed that police officers are trained on (1) what is gender, (2) gender related concepts, (3) definition, characteristics and causes of GBV,(4) categories and effects of GBV,(5) key international instruments on violence against women, national legislation on violence against women,(6) guiding principles on handling cases of GBV, step by step, procedures of handling cases of 
sexual assault, interviewing victims and witnesses, risk assessment, Post Exposure Prophylaxis (PEP) and emergency contraceptive pills.

\begin{tabular}{|ll|l|l|}
\hline Study Variables & & Training programmes & $\begin{array}{l}\text { Prevention of gender based } \\
\text { violence }\end{array}$ \\
\hline \multirow{2}{*}{ Training programmes } & Pearson Correlation & 1 & $.530^{*}$ \\
& Sig. (2-tailed) & & .000 \\
& $\mathrm{~N}$ & 412 & 412 \\
Prevention of gender & Pearson Correlation & $.530^{*}$ & 1 \\
based violence & Sig. (2-tailed) & .000 & 412 \\
& $\mathrm{~N}$ & 412 & \\
\hline
\end{tabular}

*. Correlation is significant at the 0.05 level (2-tailed).

Table 3. 3. Correlation Matrix for police training programmes and police officers prevention of gender based violence in Uganda.

Table 3.3 shows that there is a moderate positive relationship between training programmes and prevention of gender based violence, $(\mathrm{r}=0.530, \mathrm{p}=0.000, \mathrm{n}=412)$. The relationship is statistically significant at $95 \%$ confidence level since p-value (Sig.) is less $0.050(=0.000)$. This means that improvements in Training programmes during police officers' training shall be related to improvements in prevention of gender based violence. Similarly decline in training programmes during police officers' training shall be related to decline in prevention of gender based violence.

Regression analysis was used to establish the influence of training programmes on police officers prevention of gender based violence in Uganda and this was guided by the following hypothesis:

Hypothesis: Police training programmes influence police officers participation in the prevention of gender based violence.

\begin{tabular}{|l|l|l|}
\hline $\mathrm{R}$ & R Square & Adjusted R Square \\
\hline $0.530^{\mathrm{a}}$ & .281 & .279 \\
\hline
\end{tabular}

a. Predictors: (Constant), Training programmes

Table 3. 4. Model Summary

Table 3.. 4 shows Pearson's correlation coefficient $(\mathrm{R}=0.530)$, Coefficient of determination or $\mathrm{R}$ Square of 0.281 and Adjusted R Square of 0.279. An adjusted R Square of 0.279 means that Training programmes accounts for $27.9 \%$ of the variance in police officers prevention of gender based violence in Uganda. This means that when other factors are inserted in the regression model the magnitude of influence may change. Therefore training programmes with gender based violence content is one of the many factors that prevent gender based violence in Uganda. To assess the overall significance of the regression model for training programmes and police officers prevention of gender based violence in Uganda, Analysis of Variance (ANOVA) and regression coefficients were generated and the results are presented in the table 3.5 .

\begin{tabular}{|l|l|l|l|l|l|l|}
\hline ANOVA & Df & F & Sig. & $\begin{array}{l}\text { Coefficients } \\
\text { Coefficient }\end{array}$ & Sign \\
\hline Regression & 1 & 160.029 & 0.000 & 0.530 & 12.650 & .000 \\
\hline
\end{tabular}

a. Dependent Variable: Prevention of gender based violence

b. Predictors: (Constant), Training programmes

Table 3. 5. ANOVA and regression coefficients for training programmes and prevention of gender based violence in Uganda.

In determining whether a regression model is significant, the decision rule is that the calculated p-value (level of significance) for ANOVA must be less than or equal to 0.05. Since the calculated p-value of 0.000 is less than 0.05 , the regression model was found to be statistically significant $(\mathrm{F}=160.029, \mathrm{df}=1, \mathrm{p}<0.05(=0.000))$. This means that training programmes have a statistically significant influence on police officers prevention of gender based violence in Uganda. Furthermore to establish whether training programmes are predictors of police officers prevention of gender based violence and determine the magnitude to which training programmes influence police officers prevention of gender based violence, Standardized Beta and t Coefficients were generated. For the magnitude to be significant the decision rule is that the $t$ value must not be close to 0 and the p-value must be less than or equal to 0.05 . Since the t- value of 12.650 isn't close to 0 and $p$-value $<0.05(=0.000)$, the study confirmed that training programmes are predictors of police officers prevention of gender based violence. A standardized Beta coefficient of 0.530 means; every 1 unit increase in training programmes will lead to an increase of 0.530 units of police officers prevention of gender based violence.

Research findings from correlation analysis established that training programmes have a strong positive statistically significant relationship with police officers prevention of gender based violence. Findings from 
regression analysis confirmed that training programmes have a statistically significant positive influence on police officers prevention of gender based violence. Therefore the question; How have police training programmes influence police officers participation in the prevention of gender based violence in Uganda, was answered as follows:Every 1 unit increase in training programmes will lead to an increase of 0.530 units of police officers prevention of gender based violence. Furthermore, the hypothesis that was stated as thus; "Police training programmes influence police officers participation in the prevention of gender based violence” was accepted.

\subsection{CONCLUSIONS AND RECOMMENDATIONS.}

In conclusion, the study findings revealed that training programmes with gender based violence prevention content have a moderate positive statistically significant relationship on police officers prevention of gender based violence, that training programmes with gender based violence prevention content have a statistically significant positive influence on police officers prevention of gender based violence and that police training programmes with gender based violence content are predicators of police officers participation in gender based violence prevention. It was concluded that improvements in training content, materials used, assessment strategies and instructional strategies would have a positive influence on gender based violence prevention in terms of; prevention of GBV through a number of ways, for example by carrying out community policing on radios, televisions, newspapers and other forums on issues related to GBVP; partnering with other stakeholders like JLOS and NGOs to prevent GBV in Uganda; enforcing laws related to GBV by arresting, investigating and prosecuting suspects; providing psychosocial services to both victims and perpetrators of GBV; establishing some departments to expedite matters related to GBV, and these include the department of child and family protection, the department of women affairs, the department of sexual and gender based violence; joining some international and regional organisations that deal with GBV such as the Kigali declaration.

However, it was also concluded that police training programmes are facing challenges such as inadequate curricula, inadequate assessment and instructional strategies, inadequate infrastructures and training aids, inadequate funding, understaffing of CFPU, SGBV and women affairs departments, inability to provide communication skills, lack of operationalization of some departments to the lowest police administrative units, and inability to enable police officers provide sufficient referrals and psychosocial services to victims and perpetrators of GBV among others.

The study recommends that Police management should allocate more funds and resources to training programmes to enhance standardization of training through curricula, syllabi and manuals development as well as monitoring and evaluation activities. Focus should be on the introduction of sign language, French and Arabic at the initial courses. This will enhance their job performance in the contemporary world. More funding will also enable improvements in scientific methods of policing, infrastructures, equipment and transport.

\section{REFFERENCES}

Kimani, M. (2007), in Wanjohi .A.N (2016). The effectiveness of police gender desks in addressing gender based violence. A case study of Nyandarua county-Kenya.

Lockwood, D. \& Prohaska, A. (2015). Police officer Gender and Attitudes toward Intimate Partner

Violence. How Policy can eliminate Stereotypes. International Journal of Criminal Justice Sciences. Vol 10, Issue 1.

Cara, E., Rabe-Hemp, \& Amie, M. S. (2007). Violence Against Police Officers. Are female officers at Greater risk? Sage Journals. https://doi.org/10.1177/1098611107304326.

Center for Domestic Violence Prevention (2015). A call on Ugandan Police Force to curb Gender

Based Violence in Uganda through law enforcement, Kampala.

Felson, R. \& Pare, P. (2005). The reporting of Domestic Violence and Sexual assault by non-strangers to the police. Pennsylvania state University.

Institute of Economic Affairs (2009). Status of gender desks at police stations in Kenya. A case study of Nairobi province, Nairobi: Institute of Economic Affairs-Kenya.

Joeden-Forgery, E. V. (2012). Gender and the Future of Genocide studies and prevention. Genocide Studies and Prevention. Volume 7/2012, issue 1, article 10.

Marissa, L. \& Legaspi, M. (2015). Response of PNP Women's Desk officers to violence against women in Cavite. European Scientific Journal.

National Gender and Equity Commission of Kenya, (2014), in Wanjohi. A. N(2016). The effectiveness of police gender desks in addressing gender based violence. A case study of Nyandarua county -Kenya.

Ndenje, N. F. (2014). Assessment of the effectiveness of Tanzania Police Gender Desks, MST- Department of Gender and Development studies.

Oehme, K., Prost, S. G. \& Saunders, D. G. (2016). Police Responses to Cases of Officer -Involved Domestic Violence: The Effects of a Brief Web-Based Training. Downloaded from

http://policing.oxfordjournals.org/at Florida state university. Accessed on 12/01/2018 at 10:30 am. 
Policy Brief-Forum against GBV (2012). in Wanjohi, A. N. (2016). The effectiveness of police gender desks in addressing gender based violence. A case of study of Nyandarua county-Kenya.

Retief, Rand Green, S. (2015). Some Challenges in Policing Domestic Violence. Social work (Stellenbosch.Online) vol.51 n.1 Stellenbosch.

Sreekumaran, N., Shrinivas, D., Bhumika, T. V., Trupati, D, Maria, M, Dajashwari. D., Ratheebbai, V.

\& Anjali, D. (2017). Gender- responsive policing initiatives designed to enhance confidence, satisfaction in policing services and reduce risk of violence against women in low and middle income countries. A systematic review. London. EPPI- Centre, social science Research unit, VCL Institute of Education , University of London.

Uganda police force (2006). Police Act cap 303. Government of Uganda. Kampala, Uganda.Uganda

Police Force (2014). Uganda Police Force Training Policy. Associated Business Machinery,

Kampala, Uganda.

Uganda Police Force (2015). Curriculum for the Cadet Officers initial training programme, leading to the award of a post graduate diploma in police, Associated Business Machinery, Kampala, Uganda.

Uganda Police Force (2015). Curriculum for the Probationers Police Constables initial training programme, leading to the award of a diploma in Police, Associated Businness Machinery, Kampala, Uganda

Uganda Police Force (2018). The Uganda Police Force Gender Policy 2019-2023. Towards a More Gender Responsive and Effective Police Force.

Uganda Police Force. (2019). The Children Diversion Guidelines For Police Officers.

UNIFEM, (2009). Gender sensitive police reform in Rwanda and Timor. New York, UNIFEM.

United Nations High Commission for Human Rights, UNHCHR \& Uganda Police Force, UPF. (2012).

Human Rights, Gender Based Violence and Child Protection. A Trainers Guide for Uganda Police Force. Kampala, Uganda.

United Nations Office on Drugs and Crime (2010), in Wanjohi. A. N (2016). The effectiveness of police gender desks in addressing gender based violence. A case study of Nyandarua county-Kenya.

United Nations Population Fund, (2008) in Wanjohi. A. N (2016). The effectiveness of police gender desks in addressing gender based violence .A case study of Nyandarua county -Kenya.

United Nations Resolution 1325 that focuses on specific issues related to women in conflict.

United States Government (2012). United States Strategy to Prevent and Respond to Gender-Based

Violence Globaly. U.S Department of State and U.S Agency for International Development.

UNODC (2013). Annual Reports -United Nations Office on Drugs and Crime.

UPF (2018). The Uganda Police Force Gender Policy (2019-2023), Towards a More Gender Responsive and Effective Police Force

Wanjohi, A. N. (2016). The effectiveness of police gender desks in addressing gender based violence. A case of Nyandarua County-Kenya 